\title{
COVID-19 and aging, a tale of two pandemics
}

\author{
As a physician scientist caring for older adults in New York City during the peak of the COVID-19 pandemic, \\ I reflect on my experiences, the stark contrast in resource availability between hospitals and nursing homes, \\ and the scientific opportunities and challenges for aging research.
}

\section{Mark S. Lachs}

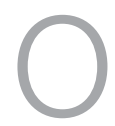

n 15 March 2020, I returned from a short sabbatical to my role as a physician scientist at Weill Cornell Medicine and Director of Geriatrics for its affiliated NewYork-Presbyterian Healthcare System, one of the largest healthcare systems in the USA. Returning from sabbatical has always been a bit anxiety provoking; putting on a stethoscope again after a break is a bit like getting back on the proverbial horse after being thrown off.

But this was different. The institution I re-entered was unrecognizable from the one I left six months earlier. The corridors had only a fraction of the busy foot traffic I remembered, but the air was thick with gravitas and uncertainty. Hospital and college brass conducted daily video briefings, emphasizing the unfurling severity of the situation, while modeling remarkable cool-headedness and leadership for thousands of employees. At our peak, over 200 patients were on mechanical ventilation on our campus alone; across our system, the total number of patients with COVID-19 was closer to a thousand. And they kept coming.

Places and people were repurposed, and they stepped up bravely and willingly. Psychiatrists, dermatologists and anesthesiologists became hospitalists and intensivists. Field hospitals were rapidly erected; the neighboring Hospital for Special Surgery, an orthopedic facility, was quickly converted into a medical hospital. My own division of geriatrics and palliative medicine participated in the conversion of several beds of a psychiatric floor into a COVID-19 hospice, of which I attended. At one point, a facilities manager appeared at my door asking to check the oxygen hook up that had not been used for 25 years since my current administrative office was converted from a patient room. "They might need your office”, he told me. Mercifully, that need did not arise.

I've worked and trained at some great places over my 30 plus year medical career, but for the first time I felt compelled to e-mail my hospital Chief Operating Officer Dr Laura Forese to tell her that

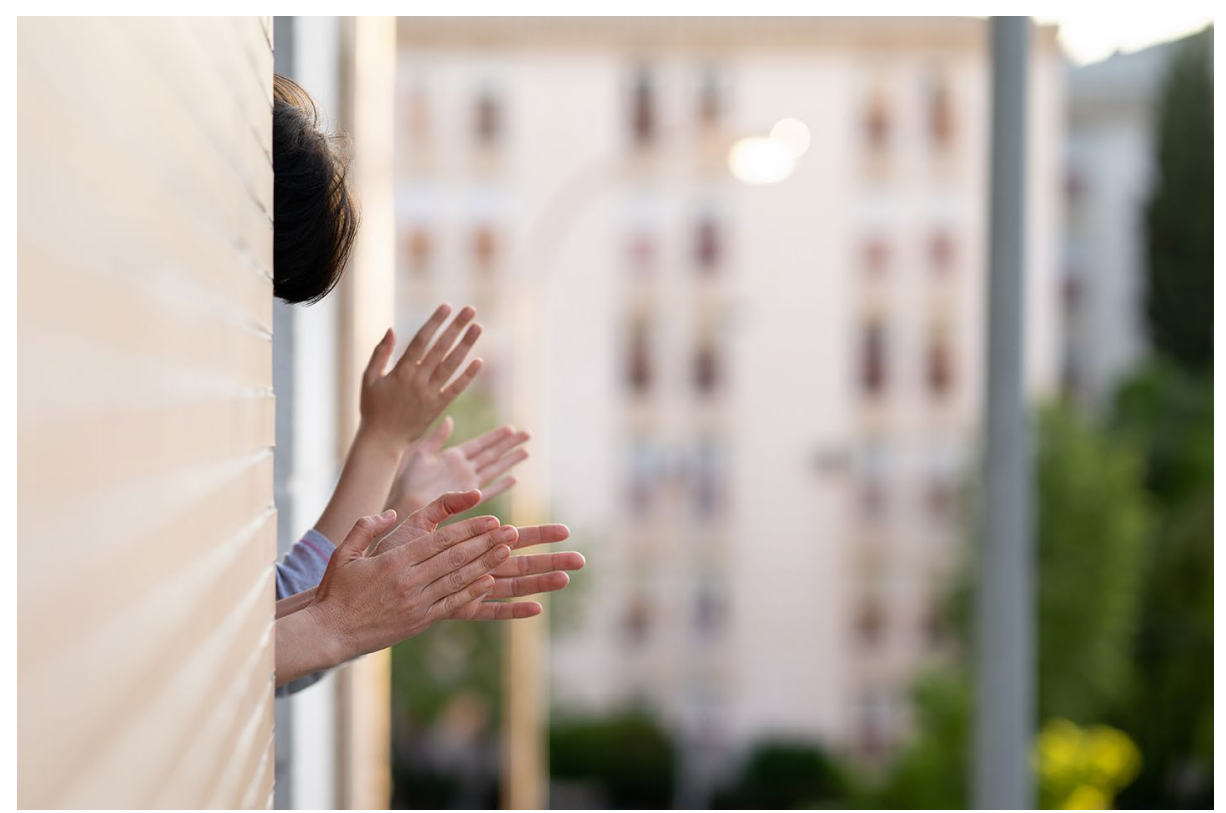

Credit: Javier Sánchez Mingorance / EyeEm / Getty

she was my new superhero, and that I had never been prouder to be an employee of any institution.

In what became a nightly 19:00 tradition, New Yorkers would clap and holler and cheer for their healthcare worker heroes from their stoops, balconies and windows. On a few occasions, I happened to be heading back to my healthcare worker hotel (also repurposed) in my scrubs. I am a geriatric internist, and it had been a long time since I donned those. Sometimes I waved bashfully to their applause.

But candidly, those ovations produced in me a curious mix of pride and embarrassment; deep down, I felt like something of an imposter. Truth be told, there were healthcare heroes everywhere, but I have come to believe that the bravest of them were working across town. I say this because elsewhere throughout the city, without fanfare or applause, another pandemic entirely was playing out, one of carnage.

\section{A tale of two pandemics}

I work at an institution of international acclaim that is extraordinarily well-run and well-resourced with medical talent and equipment. We had access to the best information, the best personal protective equipment (PPE) and the best coronavirus testing; our institutional pathologists actually invented their own serologic COVID-19 antibody test. Communication and coordination were superb. Socially distanced buses were hired to bring employees back and forth from their homes, and hotel costs and meals were reimbursed by the institution.

But my colleagues at nursing homes were under water. They had insufficient PPE and were the lowest in the food chain to acquire it. One of my nursing colleagues told me her staff were using ponchos because no gowns were available. As one of my nursing home medical director colleagues said to me, "I've never seen anything like it; I've tried everything to stop this and nothing has 
worked. It's like a hot knife through butter". That devoted geriatrician moved into one of the many vacated rooms in his facility for about a month so he could perform his duties and not bring coronavirus home to his family. The reward for his dedication: he would ultimately be hospitalized twice with the disease.

Coronavirus exposed so many things to the larger world that we gerontologists already knew; ageism, a chronically broken and underfunded system of long-term care, and the lack of expertise in geriatric medicine to name a few. But it also opened a window to many remarkable research opportunities and challenges - from basic biology to population health - that I fear will be lost as the nursing home pandemic fades from memory.

In this remainder of brief commentary, I will outline a few for posterity.

\section{Unprecedented opportunities for aging research}

By the end of May 2020, 50\% of US

COVID-19 deaths occurred in nursing homes, and in four states, the percentage exceeded $70 \%$ (ref. ${ }^{1}$ ). This unfortunate fact affords remarkable opportunities to understand basic epidemiology and transmission of this illness within, between and outside of nursing homes. I challenge readers to cite another pandemic in which a majority of cases are so profoundly concentrated to one patient population and place. This natural experiment still needs studying. Contact tracing within locked-down nursing homes may afford the best opportunity to understand transmission between patients and staff in exquisite detail not possible in larger communities. COVID-19 spread between nursing homes and communities can also be studied retrospectively with machine learning and other sophisticated methods. One example is an ingenuous cell phone geolocation study of 30 million smartphones, which showed that $7 \%$ of them appeared at more than one nursing home address in the early days of the pandemic but after nursing home lockdown. The more interconnected the facilities, the higher the COVID-19 prevalence within them ${ }^{2}$. This suggests the virus was being spread by employees working in multiple facilities, or contractors traveling to several.

Insofar as nursing homes can be reservoirs for community spread, even scientists and policy makers with no interest in gerontology should have a huge vested interest in keeping coronavirus out of unaffected facilities. My tertiary hospital can ventilate 200 patients. A community hospital with ten intensive care unit (ICU) beds will be instantly overwhelmed when coronavirus gets into the local nursing home, leaving no capacity for community cases and imperiling local healthcare workers.

How could we prevent this? Nursing homes should have the best PPE and access to testing and infection control experts. During the pandemic, they had the worst.

We should also be studying creative interventions that protected nursing home staff and residents alike. For example, during the height of the epidemic we heard of several long-term care administrators who brought mobile homes to their campuses and paid frontline staff to live in them and not return home to their families, so as not to be coronavirus vectors ${ }^{3}$. Unrealistic and expensive, you say? Here's a back-of-the-napkin cost-benefit analysis: In 2019, the average salary of a certified nursing home assistant was $\$ 29,640$ (ref. ${ }^{4}$ ); I am aware of at least one local hospital that offered $\$ 6,000$ per week for ICU nurses to come to our fair city at the height of the pandemic. Averting nursing home cases saves money, saves lives and spares healthcare worker exposures downstream. Like many things in geriatric medicine, sometimes a simple low-cost, low-tech solution is hiding right in front of us in plain sight.

Opportunities are abound with regards to health services research, aging and coronavirus, especially as the vaccine juggernaut gains steam. Will older adults be underrepresented in such trials, even though they are the most relevant population? This has been a common refrain in pharma for over 50 years. And even if older adults are included, will their less robust response to vaccination, well-known in influenza, be considered and measured? And, of course, there is the perennial anathema of low vaccination rates for those vaccines that we already know work well. Even if we were to manufacture a safe and effective vaccine, many vulnerable older adults will not choose to take it, or worse, not even have it offered to them. What drives those missed opportunities?

And finally, breakthroughs in modern geroscience should be brought to bear on coronavirus. For example, medications being tested as impactful on slowing the basic processes of aging can improve immune response in older adults. One such drug, rapamycin, has been shown to improve immune response to influenza vaccination in older adults ${ }^{5}$. The diabetes medication metformin is currently being studied in clinical trials to target the basic biology of aging ${ }^{6}$; at least one study has shown lower rates of death in diabetic patients hospitalized with COVID-19 when they were taking metformin after statistical adjustment?

And there's one more reason to care about older adults and coronavirus, even if you find my arguments about the broad scientific opportunities I've outlined unconvincing: it's the just and ethical thing to do for older adults who face daily discrimination.

\section{Mark S. Lachs ${ }^{\circledR}$}

Division of Geriatrics and Palliative Medicine, Weill Cornell Medicine, New York, NY, USA.



Mark S. Lachs is the President of the American Federation for Aging Research and the Director of Geriatrics of The NewYork-Presbyterian Health Care System.

Published online: 14 January 2021 https://doi.org/10.1038/s43587-020-00005-3

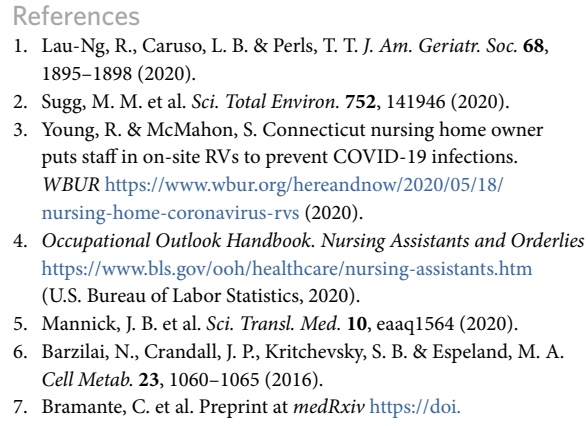

Competing interests

The author declares no competing interests. 